\title{
Facile Synthesis of Polypyrrole Nanotubes and Their Supercapacitive Application
}

Yan Yan ${ }^{1,2}$, Huiqin Li ${ }^{1,2}$, Yuan Zhang ${ }^{1,2}$, Jinqing Kan ${ }^{1,2}$, Tengfei Jiang ${ }^{1,2}$, Huan Pang ${ }^{1,2, *}$ Zhengxi Zhu ${ }^{1,2, *}$ and Huaiguo Xue $e^{1,2, *}$

${ }^{1}$ School of Chemistry and Chemical Engineering, Yangzhou University, Yangzhou, 225002, Jiangsu, P. R. China.

${ }^{2}$ Institute for Innovative Materials and Energy, Yangzhou University, Yangzhou, 225002, Jiangsu, P.

R. China.

$\dagger$ These authors contributed equally to this paper.

*E-mail: huanpangchem@hotmail.com; zhuzx@yzu.edu.cn; chhgxue@yzu.edu.cn;

doi: $10.20964 / 2017.10 .61$

Received: 20 June 2017 / Accepted: 7 August 2017 / Published: 12 September 2017

Polypyrrole nanotubes (PPy-NTs) with uniform diameters were synthesized by the situ chemical oxidation polymerization with pyrrole, methyl orange (MO) and $\mathrm{FeCl}_{3}$ as material, dopant and oxidant, respectively. The products were characterized by TEM, SEM, IR, EDS and TGA. polymerization parameters, such as the concentrations of reactants, temperature, and the types of solvents on the diameters of the nanotubes have been investigated. The results showed that the diameters of the PPyNTs can be controlled in a relatively stable value $(\sim 100 \mathrm{~nm})$ by adjusting the concentrations of reactants, temperature, types of solvents. The diameter of PPy-NTs affect the capacitive behavior of active material. The maximum specific capacitance is $960 \mathrm{~F} \mathrm{~g}^{-1}$ at $0.5 \mathrm{~A} \mathrm{~g}^{-1}$ with the concentrations of $\mathrm{FeCl}_{3}, \mathrm{MO}$ and Py are $250 \mathrm{mM}, 5.0 \mathrm{mM}$, and $50.0 \mathrm{mM}$, respectively. It also shows excellent cycle performance, after 10000 charge and discharge cycle the specific capacitance was still maintained as the original $97.1 \%$. This study basically provides a new method for controlling the composition of PPy-NTs with uniform diameter, which facilitates the development of electrochemically active materials for supercapacitors.

Keywords: polypyrrole, nanotubes; supercapacitor

\section{$\underline{\text { FULL TEXT }}$}

(C) 2017 The Authors. Published by ESG (www.electrochemsci.org). This article is an open access article distributed under the terms and conditions of the Creative Commons Attribution license (http://creativecommons.org/licenses/by/4.0/). 